\title{
REQUIREMENTS ON THE COMPETENCE OF ICT MANAGERS AND THEIR COVERAGE BY THE EDUCATIONAL SYSTEM - EXPERIENCE IN THE CZECH REPUBLIC
}

\author{
Petr DOUCEK ${ }^{1}$, Milos MARYSKA ${ }^{2}$, Ota NOVOTNY ${ }^{3}$ \\ Faculty of Informatics and Statistics, University of Economics Prague, \\ W. Churchill sq. 4, 13067 Prague, Czech Republic \\ E-mails: 1doucek@vse.cz; ${ }^{2}$ maryskam@vse.cz (correspondingauthor); ${ }^{3}$ novotnyo@vse.cz
}

Received 12 October 2011; accepted 13 January 2012

\begin{abstract}
Global developments in the information society are placing ever greater emphasis on professionals in the area of Information and Communications Technologies (ICT) and especially on managers of ICT companies. This article provides a comparison of the trends in the requirements of business practice on ICT managers in 2006 and 2010 and simultaneously draws attention to the coverage of these requirements by fields of study with ICT specialization, on the example of the Czech Republic. The presented results of the obtained data indicate quite good coverage of the requirements on knowledge and skills for the role of ICT manager in the Czech education market. In addition, the article encompasses methodology that can be employed to compare qualitative quantities of the potential of the educational process with the requirements imposed on it.
\end{abstract}

Keywords: ICT manager, competitiveness of ICT, ICT study programmes, roles in ICT, education, informatics ICT knowledge profile.

JEL Classification: A23, J01, J21, J24, O15.

\section{Introduction}

The contemporary turbulent economic environment places elevated emphasis on managerial skills in various fields. The same is also true of managerial abilities and skills in the area of introduction of information and communications technologies (ICT) into everyday economic practice and their subsequent operation. In 2010, almost $5 \%$ of the employed global population was working in positions of ICT professionals (OECD 2010, 2011; Doucek et al. 2011; Agayev, Mamedova 2012; Al-Jabri, Fraihat 2005). Their knowledge must constantly expand and, simultaneously, the typical knowledge of ICT professionals (Frinking et al. 2005) is being increasingly combined with other "not ICT" knowledge, such as marketing, business, etc. (OECD 2010; EC 2010). Similar conclusions were drawn by Fernandez (2006), who states that a combination of ICT and "not ICT" knowledge is more important for companies in selecting employees than only specific ICT knowledge. A great many authors have discussed the requirements 
on the general competence of managers e.g. Kotter 2009; Prahalad, Hamel 1996; Porter 2008; Amold, Quelch 1998; Sołoducho-Pelc, Radomska 2012, while others have concentrated on the demands placed on ICT managers (Brooks 1975; Sołoducho-Pelc, Radomska 2012; Vorisek et al. 2008; Zanda 2011; Hinton 2006; Doucek et al. 2007; Svata 2011). Similar to general practice, the university conception of the role of a manager is very varied. Managers act as heads of projects (Manwani 2010), managerial workers in company informatics (Johnson 2011), heads of working teams or groups, etc. According to Fernandez (2006); Crespo and Cota (2012), graduates of fields of study concerned only with gaining knowledge in ICT have difficulties in communication, critical thinking, creative thinking, etc. - put generally, they have difficulties in changing their thinking, especially in relation to work with information. An important factor influencing the quality of employees in all managerial positions, and thus also in the area of ICT, consists in the potential for good-quality education and the related expenditures for it. Education of professionals in the area of ICT can be classified from the viewpoint of financing into two different levels - one of these is formal education, completed by awarding a title, while the other is commercial education, which is usually completed by awarding a certificate or confirmation of completion of the course. In 2006, we began to consider the aspect of coverage of the requirements of economic entities on the individual roles of ICT professionals at the Faculty of Informatics and Statistics of the University of Economics in Prague.

\section{Formulation of the problem}

The main aspect on which we focused in our research performed in 2006, 2009 and 2011 consisted in discovering whether the fields of study concerned with teaching informatics offer their students the ability to gain, during their study (without extensive extra-curricular education) the knowledge that is required by general Czech business practice for the individual main roles in the area of company informatics. This article is concerned with presentation of the results obtained for the role of ICT manager.

\section{Methodology and data collection method}

We divided the study methodology into the area covering surveys amongst universities and surveys amongst economic entities. In addition, it was necessary to stipulate some of the starting points of the actual research, for example stipulation of ICT roles in company economics, definition of the main knowledge domains and determination of the means of measuring them.

In order to suggest suitable roles for ICT professionals, we had to define who would actually be perceived as an ICT professional. We consider an ICT professional to be an employee whose job requires specific information skills and knowledge of the creation, implementation and operation of ICT and for use of ICT in the application area. Work with ICT constitutes the main content of the employment (OECD 2010). We do 
not consider an end user of ICT, who has a specialized activity that does not affect the work of other ICT users, to be an ICT professional. The reason for not including end users amongst ICT professionals consists in the fact that an ever increasing number of professionals (physicians, financiers, architects, accountants, etc.) are employing ICT in their work and the results of the study concerned only with ICT professionals could become distorted in this case. However, for the purpose of our study, the above definition is still insufficiently narrow, because ICT professionals can work in a number of roles that are quite different from the viewpoint of the necessary skills and knowledge (e.g. comparison of the requirements on a programmer and the manager of an ICT department in a company).

Thus, for the purpose of this study, in 2006 we established six basic roles of ICT professionals (in cooperation with professional associations of ICT professionals and companies - the Czech Association of Managers in Information Technology CACIO and the ICT Unie): business analyst - architect, manager of ICT (information and communications technologies) development and operation, dealer in ICT products and services, developer/IS (information systems) architect, administrator of applications and ICT infrastructure, advanced ICT user - methodologist.

In 2010, after consultations with professional associations of ICT professionals and companies, we slightly changed the roles and established the following seven roles of ICT professionals: business analyst-architect, manager of ICT development and operation, dealer in ICT products and services, developer/IS architect, administrator of applications and ICT infrastructure, supervisor, pedagogue, scientific worker in ICT and ICT enterprise architect. The importance of supplementing the role of ICT enterprise architect is mentioned, for example, in Gala and Jandos (2010), Kunstova (2010).

We described each of these roles in structured form. In the description of each role, we identified the usual names of the professions employed in practice that can be included in this role. We also supplemented the roles by key knowledge and activities that we consider to be connected with the particular role (Doucek et al. 2007).

\section{Role of an ICT manager}

On the basis of study of the competences of managers and consultations with ICT professionals in the academic sphere and also managers in the business sphere, we arrived at the following detailed specifications of the role of ICT manager given in Table 1.

\subsection{Categories of knowledge}

In cooperation with the association of ICT managers, we formulated the requirements on obligatory knowledge and skills of ICT professionals, required in all the roles. We consider that they include particularly a high degree of creativity in resolving tasks, good knowledge of the English language (written and spoken), ability to work in a team and communication abilities and also, e.g. the ability to learn from practical examples. We did not determine these skills in the study. 
Table 1. Roles of an ICT manager

\begin{tabular}{|c|c|}
\hline ICT MANAGER & Key knowledge: \\
\hline $\begin{array}{l}\text { Manager of ICT } \\
\text { development and } \\
\text { operation }\end{array}$ & $\begin{array}{l}\text { - methods of management of the business - informatics relation } \\
\text { (how to employ ICT to promote attaining business targets), } \\
\text { - how to organize and manage development and operation of } \\
\text { ICT services, processes and sources, } \\
\text { - how to manage and coordinate ICT projects, } \\
\text { - how to register and plan ICT sources, } \\
\text { - how to measure and evaluate ICT costs and benefits, } \\
\text { - legislation affecting the use of IS/ICT. }\end{array}$ \\
\hline $\begin{array}{l}\text { Profession } \\
C I O, \\
\text { project manager, } \\
\text { operations manager, } \\
\text { safety manager; } \\
\text { ICT quality manager, } \\
\text { ICT economics manager }\end{array}$ & $\begin{array}{l}\text { Activities: } \\
\text { - preparing information strategy, } \\
\text { - preparing sourcing strategy (which services, processes and } \\
\text { sources to own/internally administer and which to purchase } \\
\text { from partners), } \\
\text { - management of an ICT project, } \\
\text { - management of information services (service delivery), } \\
\text { - management of IS/ICT operation, } \\
\text { - problem and change management, } \\
\text { - management of risks connected with ICT use, } \\
\text { - ICT safety management, } \\
\text { - ICT economics management, } \\
\text { - ICT quality control and audit, } \\
\text { - management of relations with clients and suppliers. }\end{array}$ \\
\hline
\end{tabular}

Note: knowledge of globally the best procedures in combination with knowledge of the local conditions and company culture is required (off-shore outsourcing of these activities is improbable).

We related the definition of obligatory knowledge and skills to the definition of knowledge domains in the sense of communicable words (pedagogical process) or practical exercises of acquired knowledge and skills. Here we defined the knowledge and skills that are required for the individual roles with various levels of necessity. We also classified them on the basis (Strawman 2004) of the following knowledge domains: MS01 Process modeling, MS02 Functionality and customization, MS03 Management IS/ICT and definition of ICT services and operational variants, MS04 Analysis and design (company information system as a whole and its parts), MS05 Software Engineering (technology and procedures in creation of program products), MS06 Data and information engineering, MS07 IS/ICT knowledge, MS08 Operational excellence, MS09 Team leadership skills, MS10 ICT market knowledge, MS11 Organizational management methods, MS12 Enterprise finance and economics, MS13 Sales and marketing, MS14 Mathematics, MS15 Law, MS16 Knowledge in business sectors.

We described each of these knowledge domains so that the respondents in the survey would be capable of assigning ECTS (European Credit Transfer and Accumulation System) credits obtained by the students in the subject areas to the relevant domains. The individual domains, their description and mapping between the various surveys are described, e.g. in Maryska et al. (2010). 


\subsection{Level of knowledge}

The volumes of ECTS credits that students can obtain on the basis of their studies in the individual knowledge domains were recalculated on a nonlinear six-level scale. We established the method of recalculation as follows: 0 - No knowledge, 1 -General overview of the subject matter (corresponds approximately to 1-2 ECTS instruction credits), 2 - Basic orientation in the subject matter and terminology (corresponds approximately to 3-5 ECTS instruction credits), 3 - Good overview of the subject matter and basic practical skills (corresponds approximately to 6-20 ECTS instruction credits), 4-Good overview of the subject matter and good practical skills (corresponds approximately to 21-40 ECTS instruction credits), 5 - Highest knowledge quality - deep up-to-date knowledge and advanced practical skills (corresponds approximately to 41 or more ECTS instruction credits).

On the basis of a discussion with representatives of universities and enterprises in the ICT area, we decided to employ this scale also for questioning companies. For companies, we replaced the number of ECTS credits for economic entities by the more comprehensible term "number of days of training". The recalculation mechanism was chosen as the ratio 1 ECTS credit $=1$ day of training. We arrived at the equivalence 1 ECTS credit equals one day of training, i.e. 8 hours, after analyzing the teaching plans for subjects in informatics in the Czech Republic, Germany, Austria and Poland. This corresponds to direct effective teaching.

\subsection{Knowledge profiles and their distances}

The set of knowledge that is expected for each of the defined professional roles is termed the knowledge profile of the professional role in our research. A defined knowledge profile is employed for comparison between the requirements of business practice on ICT knowledge and that offered by universities through their fields of study.

The distance between the knowledge profile of the field of study and the knowledge profile of the particular professional role indicates the number of days that the economic entity must invest into a newly employed ICT professional (graduate) from such a field of study for him (her) to attain the minimum required level of knowledge that the economic entity requires for the particular professional role. If the particular field of study exceeds the requirements in a certain domain, the distance is zero. Thus, in calculating the distance, it is necessary to determine the sum of the inadequacies in the knowledge profile of the given field of study compared to the knowledge profile of the particular professional role.

Following discussions with representatives of enterprises and professional companies, we considered that 60 days of training is an acceptable limit to the number of days of extra training (acceptable distance), where the graduate is still not too expensive for the economic entity. 


\subsection{Basic scheme of the study}

In order to obtain answers to the questions that we formulated at the beginning of the research, we decided to collect data in two areas - in the academic sphere, which provides education in the area of ICT and amongst economic entities employing ICT professionals.

\section{Research in the academic sphere}

We performed the study amongst universities providing instruction in ICT as an exhaustive study. We identified the relevant schools on the basis of information from the Institute for Information in Education and from the Ministry of Education, Youth and Sports. We performed the survey repeatedly in 2006, 2009 and 2011. This article will consider only the results of the research conducted in 2006 and 2011.

Through analysis of the Ministry of Education, Youth and Sports and IIE documents, we identified a total of 376 fields of study teaching ICT. These fields are taught at 71 faculties of universities in the Czech Republic.

We performed the survey using a structured questionnaire, which was sent to universities in paper form as a letter and an internet application was also prepared for its completion. After the end of the deadline for completing the questionnaire, those universities that had not sent in their questionnaires by the set deadline were contacted by telephone. The response rate for the questionnaires is given in Table 2 .

Table 2. Response rate for survey, 2011

\begin{tabular}{lccc}
\hline & Universities & Faculties & Fields \\
\hline Identified & 31 & 71 & 376 \\
\hline Answers & 21 & 29 & 196 \\
\hline Response rate in percent & 68 & 41 & 52 \\
\hline
\end{tabular}

\section{Data collection method}

We performed the study amongst universities providing instruction in ICT as an exhaustive study and thus, in relation to this fact, we did not use any specific data collection method. We partly reconstructed the characteristics of universities that did not send in completed questionnaires on the basis of the official data sources of the Ministry of Education, Youth and Sports. The reconstruction of data was related only to the quantitative characteristics of the fields of study, which included the number of students newly registered for study in ICT fields of study, the numbers studying in ICT fields of study, the number of graduates and the number of unsuccessful students in ICT fields of study. The lacking qualitative data, i.e. information on the numbers of credits that the students can obtain by studying the investigated fields of study, were not filled in and these fields of study were not taken into consideration in the analyses of the results and were designated as an "unclassified" segment. 
We monitored several variables in the survey:

- the total number of students newly registered for study in ICT fields of study, the numbers studying in ICT fields of study, the number of graduates and the number of unsuccessful students in ICT fields of study. We determined these characteristics for the 2001-2009 period, for which data are available in the official statistics of the Institute for Information in Education and the Ministry of Education, Youth and Sports;

- the number of credits that students can obtain in their study for each of the 16 analyzed knowledge domains;

- key identification data for the fields of study - whether this is a classical bachelor's, subsequent master's (connected two-year study after completion of bachelor's study) or five-year master's study program (five-year master's study programs are the "pre-Bologna" fields of study, whose recertification was completed in the 2006/2007 school year and which are now gradually being terminated).

\section{Survey amongst economic entities}

As of December 31,2005, there were a total of 1,266,336 active economic entities in the Czech Republic; this number had increased to 1,399,983 entities by December 31, 2010. The first classification criterion of economic entities was the number of employees. On the basis of this number, we divided economic entities into the following six groups: 0 , 1-9, 10-49, 50-249, 250-999, 1,000 or more (see Table 3).

The second classification criterion was the kind of activity performed by the entity (see Table 3). The Czech Statistical Office differentiates 17 main sectors on the basis of ISCO classification. These sectors can be divided into three groups on the basis of the level of requirements and dependence of the sector on ICT:

- sectors with the lowest requirements and dependence on ICT (MIT),

- sectors with medium requirements and dependence on ICT (SIT), and

- sectors that are completely dependent on ICT (VIT).

Table 3. Sector map for business units in the Czech Republic, 2005

\begin{tabular}{lrrrrrrr}
\hline & \multicolumn{1}{c}{0} & $1-9$ & $10-49$ & $50-249$ & $250-999$ & $1,000+$ & Total \\
\hline MIT & 263,289 & 49,914 & 14,270 & 4,317 & 369 & 87 & 332,246 \\
\hline SIT & 697,380 & 138,555 & 28,014 & 6,217 & 1,164 & 182 & 871,512 \\
\hline VIT & 49,851 & 9,590 & 2,216 & 710 & 170 & 41 & 62,578 \\
\hline Total & $1,010,520$ & 198,059 & 44,500 & 11,244 & 1,703 & 310 & $1,266,336$ \\
\hline
\end{tabular}

\section{Data collection method}

We performed a selective survey amongst economic entities.

Thus, the basic set of economic entities was thus divided into 18 strata on the basis of six size categories and three categories based on the demands of their branch of application on the use of information technologies. Probability sampling without replacement was performed for the individual strata. There is no unambiguously identifiable 
subgroup of economic entities in the sample of examined economic entities. This fact is a result especially of the sizes of the economic entities, which cover a wide range of values. This is then related to the fact that the number of ICT professionals in the examined economic entities is similarly variable. We took into account all these facts in preparation of the survey in that we required a greater fraction of examined economic entities in all the entities in the given subgroup for subgroups where a smaller number of entities could be anticipated (e.g. large entities with high dependence on ICT).

A private company whose sphere of business consisted in performance of surveys carried out the survey amongst the economic entities. The survey was performed by the CAWI (Computer Aided Web Interviewing) and CATI (Computer-Assisted Personal Interviewing) methods. In the survey in 2006, the surveyed sample was set at 1,002 entities (see Table 4).

Table 4. Structure of the observed sample, 2006

\begin{tabular}{lccccccc}
\hline & 0 & $1-9$ & $10-49$ & $50-249$ & $250-999$ & $1,000+$ & Total \\
\hline MIT & 56 & 28 & 28 & 28 & 37 & 16 & 193 \\
\hline SIT & 56 & 56 & 56 & 56 & 71 & 36 & 331 \\
\hline VIT & 56 & 110 & 160 & 122 & 26 & 4 & 478 \\
\hline Total & 168 & 194 & 244 & 206 & 134 & 56 & 1,002 \\
\hline
\end{tabular}

We performed the second survey at the end of 2010 and it was also carried out utilising the experience and base of a private company that performs surveys as its sphere of business. The structure of the sample of economic entities in the survey performed in 2010 differed slightly from the first survey. There was a fundamental change in the classification of the economic entities on the basis of the number of employees. In the second survey, we distinguished only three groups of employees. We excluded the groups with 0 and 1-9 employees from the survey on the basis of experience from the first survey in 2006 and on the basis of recommendations of experts from the Czech Statistical Office. The groups with 250-999 and 1,000+ employees were combined in group 250+. The final sample of economic entities contained 1,011 economic entities in the division according to Table 5.

The factor of dependence of the entities on ICT remained with the same conditions as were established in the survey in 2006.

Table 5. Structure of the observed sample, 2010

\begin{tabular}{lcccc}
\hline & $10-49$ & $50-249$ & $250+$ & Total \\
\hline MIT & 45 & 46 & 44 & 135 \\
\hline SIT & 57 & 474 & 98 & 629 \\
\hline VIT & 66 & 142 & 39 & 247 \\
\hline Total & 168 & 662 & 181 & 1,011 \\
\hline
\end{tabular}


Determined facts:

- The number of ICT professionals per economic entity in 2010 classified into seven roles (see subsection 2.1). The anticipated number of ICT professionals employed in the entities in the next five years.

- Requirements on the level of knowledge in the individual working positions classified in 16 knowledge domains (for more details, see subsection 2.2) ${ }^{1}$.

- Other variables that affect the entities and their requirements on ICT professionals are: the number of employees, sector of the economy on which the entity performs its economic activities, requirements of the economic sector on ICT, suppliers of ICT for entities, clients of the ICT entity, domestic or foreign owner of the entity.

- Requirements on knowledge in the individual roles.

\subsection{Principles of data processing and their evaluation}

In relation to the further performed statistical analysis of the answers of the respondents in the survey, we evaluated the variables mainly by the statistical method of the median. We employed the technique of box plots (for sampling distributions) and scatter plots (for medians) (Pecakova 2010; Vojacek, Pecakova 2010) to compare the differences in the individual professional roles and differences in knowledge categories.

The data obtained from respondents were processed by the methods and instruments of cluster analysis with support from the instruments of the MS SQL Server 2008 R/2 platform. In the context of the principles of cluster analysts, it should be added that we used EM (expectation-maximization) algorithms (Bilmes 1998; MacLennan et al. 2009).

\section{Data analysis - clustering and distance}

The methods and instruments of cluster analysis enabled us to determine clusters of fields of study with similar characteristics.

During the study and based on the determined data, the fields of study providing education in the ICT area were collected in four clusters of bachelor's fields of study and four clusters of master's fields of study. The median of the determined values was used to express the level of knowledge in each cluster. The determined values were expressed graphically using spider-web charts. We used them to compare the determined values both within the individual clusters on the part of what is offered (survey in the academic sphere) and also for the knowledge that is required by the economic entities for performance of the individual ICT professional roles.

Comparison of the requirements of the economic entities with what is offered by the academic sphere enabled us to identify the distance between what is offered and the requirements on the knowledge of ICT professionals. This served as an indicator for determination of whether the composition of subject matter and structure of the fields of

\footnotetext{
${ }^{1}$ In each knowledge domain, knowledge is evaluated on a nonlinear scale " 0 - no knowledge ( 0 days of training)" ... "5 - highest level of knowledge (more than 41 days of training)" (for more details, see subsection 2.3).
} 
study corresponds to the requirements of the economic entities for the individual roles of ICT professionals or not. The values determined in this indicator can be considered to correspond to the number of additional days of training that a graduate of the relevant ICT field of study must undergo after entering employment at the economic entity to attain the minimum required level of knowledge.

\section{Results}

In the survey amongst economic entities in 2010, we distinguished a total of seven roles of ICT professionals (see subsection 2.1). This article is concerned only with the presentation role of ICT managers that, according to Ihned (2011), is considered to be one of the most attractive roles in the labour market (Potuzakova, Mildeova 2011).

The results of the analysis also provide the most important conclusions and statistical evaluation of the determined characteristics both for the demand for the role of ICT manager on the part of economic entities and also for the supply of graduates created for this role by universities. The supply provided by the academic sphere and the demand amongst economic entities are analysed taking into account the factor of time in 2006 and 2010 , or 2011 .

\section{Survey amongst economic entities}

It was the purpose of the survey amongst the economic entities to determine which knowledge the economic entities require in university graduates aspiring to the role of ICT manager. Processing the results of the survey using the described methodology led to the following conclusions, which are set forth in Table 6 and in Figure 1.

Between 2006 and 2010, there was a reduction in the expectations of economic entities in relation to the level of knowledge that a university graduate must have in order to become an ICT manager. We recorded a reduction in requirements in more than $60 \%$ of the knowledge domains. The values given in Table 6 unambiguously confirm that, between 2006 and 2010, there was a reduction in requirements on expected knowledge in 10 of 16 knowledge domains and that the expected knowledge levels did not change in the remaining 6 knowledge domains. It is interesting that there was a reduction in expected knowledge in half of the ICT domains (MS01-MS04) in spite of the fact that these are domains that are directly related to designing company information systems.

Table 7 gives a statistical analysis of the results of the questionnaire survey performed amongst economic entities in 2006. It follows from this data that the median and average have almost the same values in all the knowledge domains, which means that most of the respondents corresponded similarly and placed similar demands on knowledge in the individual knowledge domains for this role. The same conclusion also followed for analysis of the standard deviation. The minimum required level of knowledge 0 in all the knowledge domains and negative skewness value indicate that only a very few respondents answered that they expect knowledge at level 0 in the individual knowledge domains. It follows from the performed analysis that the data have homologous character. 
Table 6. Requirements of companies on role ICT manager

\begin{tabular}{|c|c|c|c|}
\hline \multirow[t]{2}{*}{ Knowledge domain } & \multicolumn{2}{|c|}{ ICT manager } & \multirow[t]{2}{*}{ Change } \\
\hline & 2006 & 2010 & \\
\hline MS01 Process modeling & 4 & 3 & $y$ \\
\hline MS02 Functionality and customization & 4 & 3 & $y$ \\
\hline MS03 Management ICT & 4 & 3 & $y$ \\
\hline MS04 Analysis and design & 4 & 3 & $y$ \\
\hline MS05 Software engineering & 3 & 3 & $\rightarrow$ \\
\hline MS06 Data and information engineering & 3 & 3 & $\rightarrow$ \\
\hline MS07 ICT knowledge & 4 & 4 & $\rightarrow$ \\
\hline MS08 Operational excellence & 4 & 4 & $\rightarrow$ \\
\hline MS09 Team leadership skills & 4 & 3 & $y$ \\
\hline MS10 ICT market knowledge & 4 & 3 & $y$ \\
\hline MS11 Organizational management methods & 3 & 3 & $\rightarrow$ \\
\hline MS12 Enterprise finance and economics & 4 & 3 & $y$ \\
\hline MS13 Sales and marketing & 3 & 2 & $y$ \\
\hline MS14 Mathematics & 3 & 2 & $y$ \\
\hline MS15 Law & 3 & 2 & $y$ \\
\hline MS16 Knowledge in business sectors & 3 & 3 & $\rightarrow$ \\
\hline
\end{tabular}

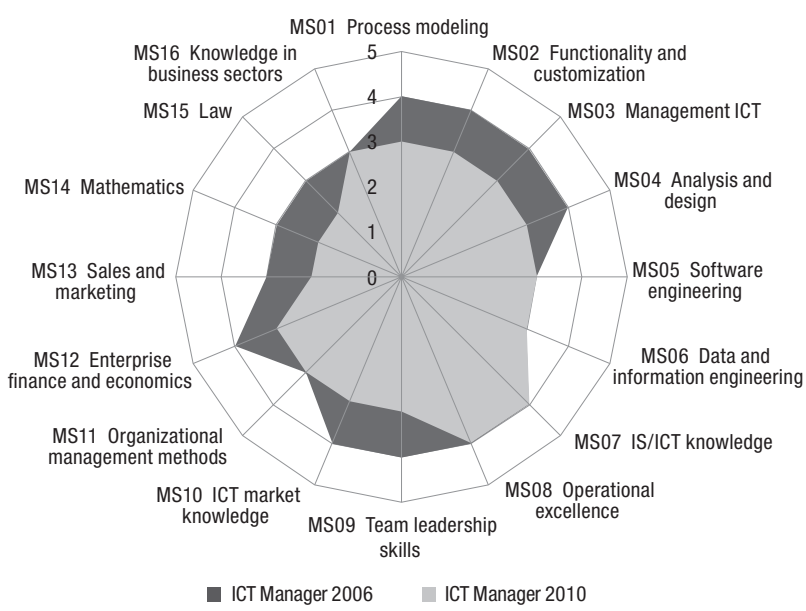

Fig. 1. Requirements of companies on the role ICT manager Source: authors. 
Table 7. Statistical analysis of companies requirements on the role ICT manager, 2006

\begin{tabular}{lcccccccc}
\hline \multirow{2}{*}{$\begin{array}{l}\text { Knowledge } \\
\text { domain }\end{array}$} & \multicolumn{7}{c}{$\mathrm{n}=1002$} \\
\cline { 2 - 9 } & Avg. & Med & Max & Min & $\sigma$ & $\sigma^{2}$ & $\delta$ & $\tau$ \\
\hline MS01 & 3.560 & 4.000 & 5.000 & 0.000 & 1.232 & 1.519 & -1.033 & 1.220 \\
\hline MS02 & 3.549 & 4.000 & 5.000 & 0.000 & 1.233 & 1.520 & -0.940 & 0.833 \\
\hline MS03 & 3.446 & 4.000 & 5.000 & 0.000 & 1.294 & 1.675 & -0.949 & 0.732 \\
\hline MS04 & 3.430 & 4.000 & 5.000 & 0.000 & 1.269 & 1.611 & -0.807 & 0.419 \\
\hline MS05 & 3.259 & 3.000 & 5.000 & 0.000 & 1.409 & 1.985 & -0.763 & 0.047 \\
\hline MS06 & 3.223 & 3.000 & 5.000 & 0.000 & 1.413 & 1.997 & -0.704 & -0.133 \\
\hline MS07 & 3.544 & 4.000 & 5.000 & 0.000 & 1.279 & 1.635 & -0.938 & 0.658 \\
\hline MS08 & 3.617 & 4.000 & 5.000 & 0.000 & 1.346 & 1.811 & -1.100 & 0.953 \\
\hline MS09 & 3.710 & 4.000 & 5.000 & 0.000 & 1.338 & 1.790 & -1.103 & 0.812 \\
\hline MS10 & 3.378 & 3.000 & 5.000 & 0.000 & 1.298 & 1.684 & -0.791 & 0.526 \\
\hline MS11 & 3.373 & 4.000 & 5.000 & 0.000 & 1.364 & 1.860 & -0.850 & 0.378 \\
\hline MS12 & 3.218 & 3.000 & 5.000 & 0.000 & 1.386 & 1.921 & -0.610 & -0.127 \\
\hline MS13 & 3.130 & 3.000 & 5.000 & 0.000 & 1.350 & 1.822 & -0.559 & -0.118 \\
\hline MS14 & 2.953 & 3.000 & 5.000 & 0.000 & 1.386 & 1.920 & -0.414 & -0.369 \\
\hline MS15 & 2.927 & 3.000 & 5.000 & 0.000 & 1.394 & 1.943 & -0.301 & -0.528 \\
\hline MS16 & 2.886 & 3.000 & 5.000 & 0.000 & 1.383 & 1.914 & -0.306 & -0.379 \\
\hline & & & & & & & &
\end{tabular}

Figure 1 supplements the information given in Table 6 . The requirements placed by economic entities on knowledge in the role of ICT manager in 2006 are shown in dark colour, while the light colour corresponds to the requirements on the same role in 2010. The high demands on knowledge are apparent in domains MS01-MS04 in 2006 - emphasis on basic ICT knowledge, MS07-MS10 - knowledge of the operation of ICT in enterprises and knowledge of the ICT market and MS-12 - knowledge of finances and trends in the ICT market. It is also interesting that, on the other hand, there was a reduction in anticipated knowledge in managerial-oriented knowledge domains (MS09MS11) in 2010. There was also a reduction in expected knowledge in basic information knowledge domains MS01-MS04, which are not essential for the managerial role at this knowledge level. The requirements on domains MS07 and MS08 - knowledge of ICT and its operation remained identical.

It follows from the data mentioned in Figure 1 that, for statistical analysis through the median and average, the determined values are close in most of the knowledge domains (with the exception of knowledge domain MS11). Thus, most of the respondents replied similarly and the data sample did not contain significantly different values that would greatly affect the average value. The same conclusion also followed for analysis of the 
standard deviation. The minimum required level of knowledge in all the knowledge domains equalled 0 . Thus, the negative skewness value $(\delta)$ is important here, as it indicates that only a very few respondents answered that they expect knowledge at 0 level. It follows from the performed analysis that the data have homologous character $(\tau)$.

Table 8 contains similar statistical analysis as Table 7, however performed on the data from the survey in 2010.

Table 8. Statistical analysis of companies requirements on the role ICT manager, 2010

\begin{tabular}{lcccccccc}
\hline \multirow{2}{*}{$\begin{array}{l}\text { Knowledge } \\
\text { domain }\end{array}$} & \multicolumn{7}{c}{$\mathrm{n}=1011$} \\
\cline { 2 - 9 } & Avg. & Med & Max & Min & $\sigma$ & $\sigma^{2}$ & $\delta$ & $\tau$ \\
\hline MS01 & 2.922 & 3.000 & 5.000 & 0.000 & 1.156 & 1.336 & -0.611 & 0.256 \\
\hline MS02 & 3.225 & 3.000 & 5.000 & 0.000 & 1.004 & 1.009 & -0.514 & 0.348 \\
\hline MS03 & 3.167 & 3.000 & 5.000 & 0.000 & 1.128 & 1.273 & -0.586 & 0.287 \\
\hline MS04 & 3.241 & 3.000 & 5.000 & 0.000 & 1.048 & 1.099 & -0.629 & 0.624 \\
\hline MS05 & 2.775 & 3.000 & 5.000 & 0.000 & 1.086 & 1.179 & -0.267 & -0.285 \\
\hline MS06 & 3.068 & 3.000 & 5.000 & 0.000 & 0.991 & 0.982 & -0.405 & 0.066 \\
\hline MS07 & 3.603 & 4.000 & 5.000 & 0.000 & 0.889 & 0.791 & -0.626 & 1.200 \\
\hline MS08 & 3.479 & 4.000 & 5.000 & 1.000 & 1.003 & 1.006 & -0.430 & -0.161 \\
\hline MS09 & 3.305 & 3.000 & 5.000 & 0.000 & 1.167 & 1.362 & -0.712 & 0.358 \\
\hline MS10 & 3.144 & 3.000 & 5.000 & 0.000 & 1.030 & 1.060 & -0.434 & 0.219 \\
\hline MS11 & 2.813 & 3.000 & 5.000 & 0.000 & 1.184 & 1.401 & -0.225 & -0.388 \\
\hline MS12 & 2.606 & 3.000 & 5.000 & 0.000 & 1.115 & 1.244 & -0.139 & -0.184 \\
\hline MS13 & 2.275 & 2.000 & 5.000 & 0.000 & 1.158 & 1.341 & -0.139 & -0.495 \\
\hline MS15 & 2.332 & 2.000 & 5.000 & 0.000 & 1.206 & 1.453 & -0.072 & -0.330 \\
\hline MS16 & 2.383 & 2.000 & 5.000 & 0.000 & 1.150 & 1.323 & 0.026 & -0.442 \\
\hline
\end{tabular}

Here, the data also exhibit homogeneous character. As anticipated, the value of the median is lower (most values are at level 3) compared to the value in 2006 (most values are at level 4). The average value of required knowledge is one knowledge level lower in 2010. It can be stated on the basis of analysis of average values that the respondents also gave similar answers here. The standard deviation is similar for all the knowledge domains and a similar conclusion to that in Table 7 also follows for the minimum values and skewness $(\delta)$. In contrast to the other statistical characteristics, mention should be made of knowledge domain MS08 that exhibits the lowest value of 1 for column Min (the others have value 0 ). Thus, all the economic entities that participated in the survey required at least minimal knowledge in this area for this knowledge domain $(\tau)$. 


\section{Survey among universities}

The analysis of the survey amongst universities in the Czech Republic was performed to determine the depth of knowledge that students can acquire during their studies at universities and the degree of accordance of the advantages of the offered education for the role of ICT manager with the requirements of economic entities. Trends in the distance between demand and supply of knowledge are an important indicator of developments in the ICT education system.

It should be recalled that we performed three surveys in the past five years (in 2006, 2009 and 2011) amongst academic institutions providing education in ICT fields of study and that this article is concerned only with the results of the surveys performed in 2006 and 2011.

\section{Bachelor's study}

We performed the first survey amongst universities in 2006. The basic statistical characteristics of the survey are given in Table 9 below.

Table 9. Statistical survey amongst schools in 2006

\begin{tabular}{lcccccccc}
\hline $\begin{array}{l}\text { Knowledge } \\
\text { domain }\end{array}$ & \multicolumn{7}{c}{$\mathrm{n}=221$} \\
\cline { 2 - 9 } & Avg. & Med & Max & Min & $\sigma$ & $\sigma^{2}$ & $\delta$ & $\tau$ \\
\hline MS01 & 1.898 & 2.000 & 4.000 & 0.000 & 1.500 & 2.250 & -0.229 & -1.540 \\
\hline MS02 & 1.546 & 2.000 & 5.000 & 0.000 & 1.474 & 2.173 & 0.197 & -1.476 \\
\hline MS03 & 1.468 & 2.000 & 4.000 & 0.000 & 1.398 & 1.955 & 0.071 & -1.741 \\
\hline MS04 & 1.949 & 2.000 & 4.000 & 0.000 & 1.429 & 2.042 & -0.307 & -1.376 \\
\hline MS05 & 2.382 & 3.000 & 5.000 & 0.000 & 1.558 & 2.429 & -0.413 & -1.025 \\
\hline MS06 & 2.420 & 3.000 & 5.000 & 0.000 & 1.268 & 1.607 & -0.748 & -0.253 \\
\hline MS07 & 2.737 & 3.000 & 5.000 & 0.000 & 1.373 & 1.886 & -0.747 & 0.097 \\
\hline MS08 & 1.526 & 2.000 & 5.000 & 0.000 & 1.420 & 2.017 & 0.143 & -1.425 \\
\hline MS09 & 1.375 & 1.000 & 5.000 & 0.000 & 1.391 & 1.934 & 0.283 & -1.443 \\
\hline MS10 & 1.133 & 0.000 & 3.000 & 0.000 & 1.300 & 1.691 & 0.438 & -1.596 \\
\hline MS11 & 1.498 & 1.000 & 5.000 & 0.000 & 1.480 & 2.189 & 0.217 & -1.547 \\
\hline MS12 & 1.495 & 1.000 & 5.000 & 0.000 & 1.558 & 2.429 & 0.283 & -1.562 \\
\hline MS13 & 1.099 & 0.000 & 4.000 & 0.000 & 1.309 & 1.713 & 0.554 & -1.350 \\
\hline MS14 & 1.959 & 2.000 & 5.000 & 0.000 & 1.428 & 2.039 & -0.311 & -1.240 \\
\hline MS15 & 1.249 & 1.000 & 4.000 & 0.000 & 1.245 & 1.551 & 0.300 & -1.459 \\
\hline MS16 & 0.980 & 0.000 & 5.000 & 0.000 & 1.626 & 2.643 & 1.371 & 0.474 \\
\hline & & & & & & & & \\
\hline
\end{tabular}


Although most of the values of the statistical analysis through the median and average of the individual knowledge domains mentioned in Table 9 have similar values, there are a number of very interesting phenomena. These can be found in knowledge domains MS05, MS10 and MS13. We will not consider knowledge domain MS05 where, although the difference in these indicators is greater, this can be readily explained similarly as for the previous table. The values for knowledge domains MS10 and MS13 are far more interesting, as the difference is more than one knowledge level. It thus follows that a large number of schools stated that the level of knowledge provided equalled 0 . This conclusion also follows from the highest value for all knowledge domains for indicator $\tau$. Compared to the other knowledge domains, the lower value of the scatter and standard deviation are affected by the maximum value of the knowledge level, which the universities in the analysed fields of study indicated as level 3 (this is level 5 in most other cases).

Similar conclusions as for the analyses in the previous tables were found in the other cases.

Figure 2 compares the requirements placed by the economic entities on the role of ICT manager in 2006 and the knowledge being offered by bachelor's fields of study in 2006 for the role of ICT manager.

It is apparent from Figure 2 that none of the examined bachelor's fields of study satisfies the expectations of economic entities for the role of ICT manager. These expectations are indicated by the dashed line. The profile of knowledge provided by the field of study in the Bc-D 06 cluster approaches most closely to the requirements of companies for the role of ICT manager. Nonetheless, the requirements of companies in this cluster are

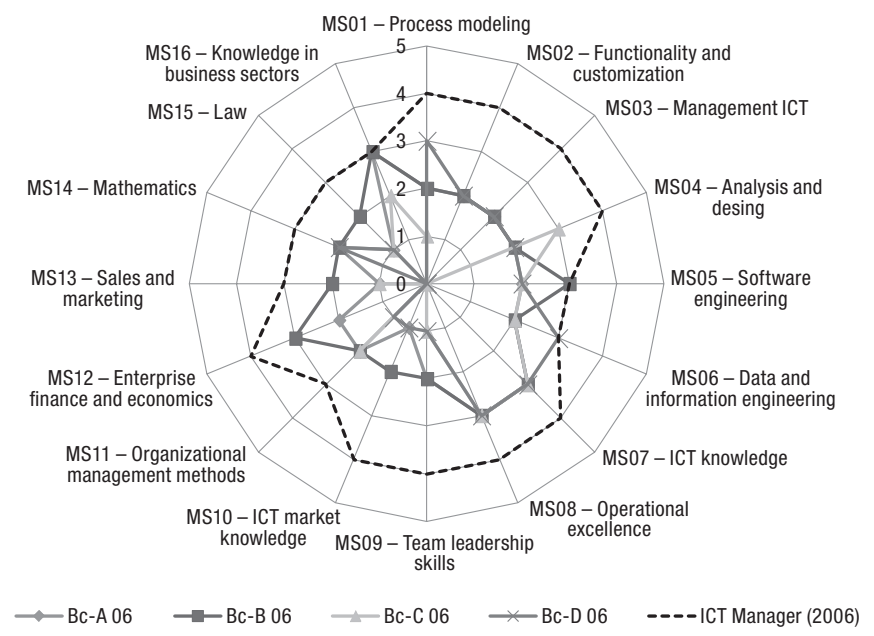

Fig. 2. Knowledge provided by bachelor's fields of study vs demand for knowledge by companies for the role of ICT manager in 2006

Source: authors. 
completely met only in knowledge domain MS06. For key knowledge domains (MS02MS04), the requirements of economic entities for the role of ICT manager are met only minimally at level 2 , although the economic entities require level 4 . Conditions are better for knowledge domains MS01, MS05, MS07 and MS08, where the difference is "only" one knowledge level (4 required and 3 provided or 3 required and 2 provided).

The knowledge profile that graduates can potentially acquire in this cluster of fields of study is very inadequate in knowledge domains MS09 and MS10, where there is a difference of as much as 3 knowledge levels (4 required and 1 provided). Similarly disappointing results in this cluster were obtained for the remaining knowledge domains.

The clusters of the other analysed bachelor's fields of study exhibit even worse results, as is shown in Figure 2.

It thus follows that, in 2006, universities educated students in bachelor's fields of study to an extent that was inadequate for the demands that economic entities place on the knowledge for the role of ICT manager.

Similar results of the statistical analysis of the results of the survey in 2006 were also found for the survey in 2011. Its statistical characteristics are given in Table 10 below.

Table 10. Statistical analysis of the surveys in schools in 2011

\begin{tabular}{lcccccccc}
\hline \multirow{2}{*}{$\begin{array}{l}\text { Knowledge } \\
\text { domain }\end{array}$} & \multicolumn{7}{c}{$\mathrm{n}=196$} \\
\cline { 2 - 10 } & Avg. & Med & Max & Min & $\sigma$ & $\sigma^{2}$ & $\delta$ & $\tau$ \\
\hline MS01 & 1.235 & 0.000 & 3.000 & 0.000 & 1.319 & 1.740 & 0.254 & -1.741 \\
\hline MS02 & 1.043 & 0.000 & 4.000 & 0.000 & 1.311 & 1.719 & 0.644 & -1.322 \\
\hline MS03 & 1.305 & 2.000 & 4.000 & 0.000 & 1.319 & 1.740 & 0.189 & -1.659 \\
\hline MS04 & 1.321 & 2.000 & 3.000 & 0.000 & 1.317 & 1.735 & 0.131 & -1.769 \\
\hline MS05 & 2.214 & 3.000 & 5.000 & 0.000 & 1.575 & 2.481 & -0.350 & -1.300 \\
\hline MS06 & 2.283 & 3.000 & 5.000 & 0.000 & 1.538 & 2.365 & -0.369 & -1.019 \\
\hline MS07 & 2.829 & 3.000 & 5.000 & 0.000 & 1.591 & 2.530 & -0.534 & -0.538 \\
\hline MS08 & 1.278 & 0.000 & 4.000 & 0.000 & 1.390 & 1.933 & 0.291 & -1.768 \\
\hline MS09 & 1.449 & 2.000 & 4.000 & 0.000 & 1.380 & 1.905 & 0.082 & -1.702 \\
\hline MS10 & 1.070 & 0.000 & 3.000 & 0.000 & 1.257 & 1.581 & 0.540 & -1.442 \\
\hline MS11 & 1.182 & 0.000 & 4.000 & 0.000 & 1.328 & 1.762 & 0.400 & -1.612 \\
\hline MS12 & 1.567 & 2.000 & 5.000 & 0.000 & 1.559 & 2.430 & 0.481 & -0.870 \\
\hline MS13 & 0.952 & 0.000 & 3.000 & 0.000 & 1.128 & 1.272 & 0.482 & -1.463 \\
\hline MS14 & 2.567 & 3.000 & 5.000 & 0.000 & 1.576 & 2.483 & -0.566 & -0.719 \\
\hline MS15 & 1.241 & 1.000 & 3.000 & 0.000 & 1.127 & 1.270 & 0.174 & -1.437 \\
\hline MS16 & 0.235 & 0.000 & 4.000 & 0.000 & 0.725 & 0.525 & 3.038 & 8.452 \\
\hline & & & & & & & & \\
\hline
\end{tabular}


It follows from Table 9 that, with the exception of a very few cases, the compared values given in the columns are the average and median. The maximum values given in column Max at levels 4 and 5 and the minimal values are at level 0 for all the knowledge domains. All the values in the skewness $(\delta)$ column are negative, indicating that only a very few respondents indicated that the knowledge gained by students during their studies is at level 0 . Indicator kurtosis $(\tau)$ shows the concentration of the collected data around the Avg. value.

If we compare the demands of the economic entities on the knowledge profile for the role of ICT manager for the data determined in 2010 (dashed line in Fig. 3), it is found that the requirements of the economic entities on the knowledge of graduates for the role of ICT manager decreased. In domains MS01-MS04, MS09, MS10, MS12, we found a reduction from level 4 to level 3 and, in knowledge domains MS13-MS16 a reduction from level 3 to level 2 was even found. It thus follows that there was a substantial reduction in demands.

In this connection, the trends in the knowledge being offered are interesting from the viewpoint of fields of study at universities. Prior to their analysis, it should be mentioned that it is not possible to compare clusters Bc-A 06 and Bc-A 11, etc., but that a general comparison must be performed without regard to their names. This is a result of the different structure of the respondents in the two surveys and their assignment to clusters.

Comparison of graphs Figure 2 and Figure 3 reveals a substantial increase in the level of knowledge taught in the fields of study, especially in domains MS05-MS07 in cluster $B c-D 11$, where this is now at level 4 compared to level 2-3 found in the survey in 2006. However, it is apparent from the graph that this positive trend in cluster Bc-D 11

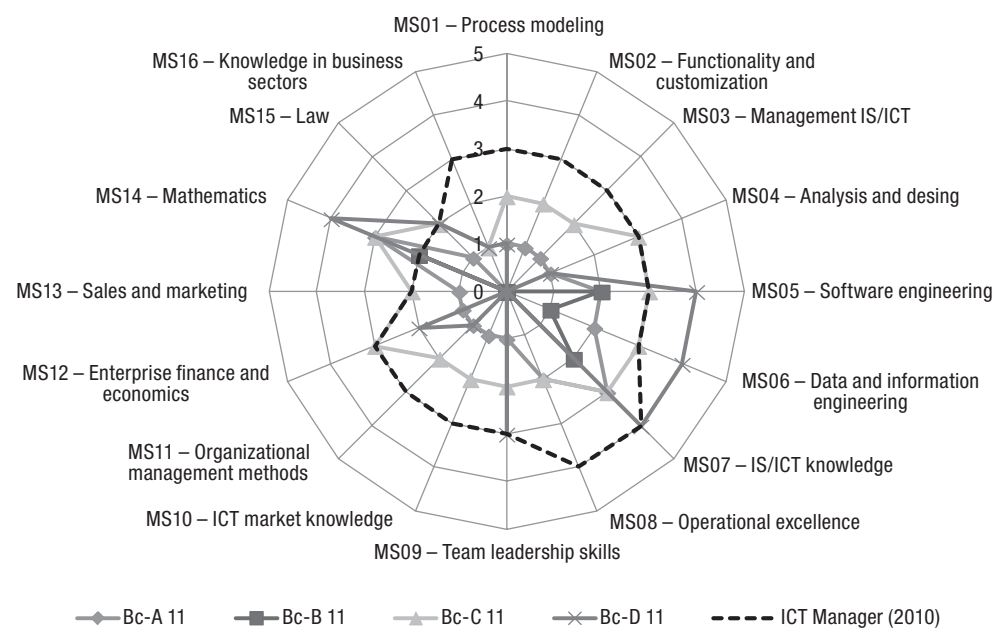

Fig. 3. Knowledge provided by bachelor's fields of study vs demand for knowledge by economic entities for the role of ICT manager in 2010

Source: authors. 
does not apply to all the knowledge domains, as no knowledge is taught in the other knowledge domains - MS02-MS04, MS08, MS10, MS11 and MS14. However, it can be stated that the fields of study in cluster Bc-D 11 are specialised in the areas of software, and data and information engineering and offer a wide range of IS/ICT knowledge. However, this is not entirely satisfactory for the role of ICT manager as they are at the very extreme limit of number of days of extra training acceptable in practice.

The situation is different in cluster $B c-C 11$, where the knowledge values in the knowledge domains are balanced at level 2 (MS01-MS03, MS08-MS11, MS13, MS15) and level 3 (MS04-MS07, MS12, MS14). Only knowledge domain MS16 is an exception as the study fields offer only knowledge at level 1.

Similar trends, although at lower knowledge levels (level 2 and level 1) are also exhibited by the remaining two clusters of fields of study $-B c-A 11$ and $B c-B 11$.

\section{Comparison of survey results - mind the gap}

The overall results of both surveys, both amongst schools and amongst economic entities, are summarized in Table 11 and Figure 4. Table 11 gives a numerical expression of the difference between the requirements of economic entities on the knowledge of graduates and the knowledge that universities enable their graduates to acquire during normal study - according to the study method, mentioned in part 2.4. The greater the value attained in the individual clusters of the field of study, the greater the number of days of extra training that the graduate of ICT study must undergo in order to meet the requirements of economic entities. Thus, it can be stated that, the higher the determined value of this distance, the more it is necessary to invest into a graduate of the given clusters in the form of additional education.

As follows from Table 11, in 2006 none of the fields of study completely fulfilled the requirements of the economic entities on knowledge for the role of ICT manager. The smallest distance was found for the survey in 2006 for cluster Bc-D; however, this distance at the level of 113 days is almost twice as large as the minimum number of extra training days, equal to 60 days, acceptable for economic entities. Cluster Bc-A is a clear signal for the educational system in the area of ICT, as this does not correspond to the requirements of economic entities at all.

Table 11. Distance between the requirements of economic entities on knowledge and the knowledge offered by university graduates

\begin{tabular}{lcc}
\hline & ICT manager -2006 & ICT manager -2011 \\
\hline Bc-A & 212 & 56 \\
\hline Bc-B & 168 & 100 \\
\hline Bc-C & 173 & 39 \\
\hline Bc-D & 113 & 58 \\
\hline
\end{tabular}


A different situation was found for the data for 2011, where there was an increase in knowledge offered by universities to their students and also a reduction on the requirements placed on graduates by economic entities. In fact, in 2011, three clusters of fields of study (Bc-A 11, Bc-C 11 and Bc-D 11) complied with expectations. We identified the best results for cluster Bc-C 11, where the distance corresponded to only 39 days of extra training, which is well below the set limit. The worst results were exhibited by fields of study in cluster Bc-B 11, where the acceptable value is exceeded by 40 days.

\section{Partial conclusions}

In the context of the above, it can be stated that there was a substantial improvement in agreement between the requirements of company practice and the knowledge offered by university graduates between 2006 and 2011. The change in agreement between supply and demand is given in Figure 4. In 2006, none of the clusters fulfilled the set condition of a maximum of 60 days of additional training, which is given as the horizontal line at the level of the value 60 on the ordinate in Figure 4. Thus, none of the clusters had a height of the relevant column in the graph below or equal to a value of 60 . In contrast, this condition was met by three clusters of study fields in 2011. However, it must be pointed out that the change occurred on the part of demand, where the requirements on knowledge decreased, as well as on the part of supply where, on the other hand, the scope of offered knowledge increased in some areas. In 2010, the best results were attained by cluster of study fields Bc-C 11 .

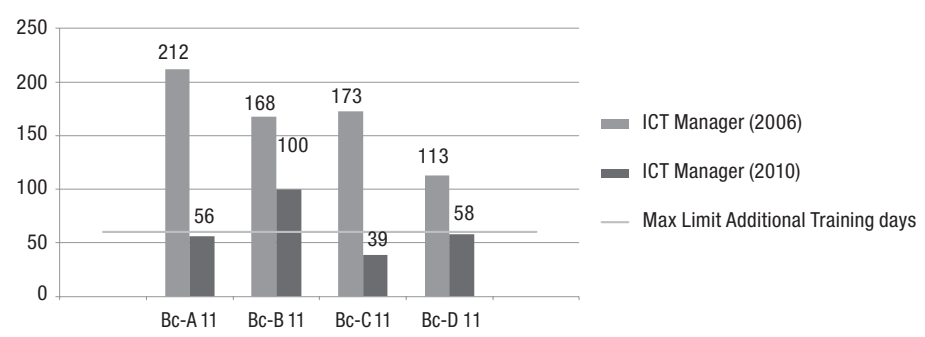

Fig. 4. Gap between the requirements of economic entities on knowledge and the knowledge offered by university graduates

Source: authors.

\section{Master's study}

The second detailed analysis that is related to analysis of bachelor's study fields consists in analysis of master's study fields.

In the context of our study, we consider master's study fields to correspond to both fiveyear master's fields of study and also to the field of study divided into bachelor's and subsequent master's study according to the Bologna declaration. For these fields of study, we combined the interconnected bachelor's and subsequent master's study fields and added together the volumes of credits accorded to the individual knowledge domains at both levels of study. In this way, we attained comparability of the five-year master's fields of study and the fields of study classified according to the Bologna declaration. 
Figure 5 provides an analysis of the determined facts for the data from 2006. It is found that the requirements on graduate knowledge are met for only two ICT knowledge domains (MS05 and MS06). The requirements are fulfilled only in knowledge domains MS11, MS14 and MS16 for non-informatics knowledge domains.

For all the clusters, it was found that the best conditions for preparation according to the requirements of business practice are provided by fields of study in cluster Mgr5-C 06, followed closely by fields of study in cluster Mgr5-D 06 (Fig. 7).

A completely different situation was found in the survey in 2011 (Fig. 6). Here it is apparent at first glance that the best results are attained by cluster Mgr5-C 11, in which expected practice is met or exceeded in knowledge domains MS01 MS06 and MS09-MS15. Expectations are not met only in three knowledge domains - MS07, MS08 and MS16.

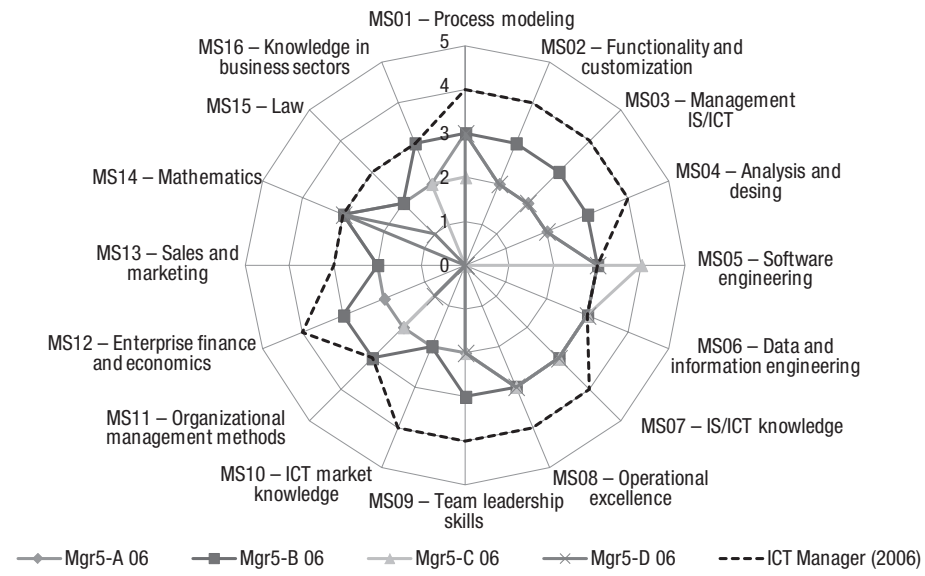

Fig. 5. Knowledge offered by master's study fields vs demand for knowledge by economic entities for the role of ICT manager in 2006. Source: authors.

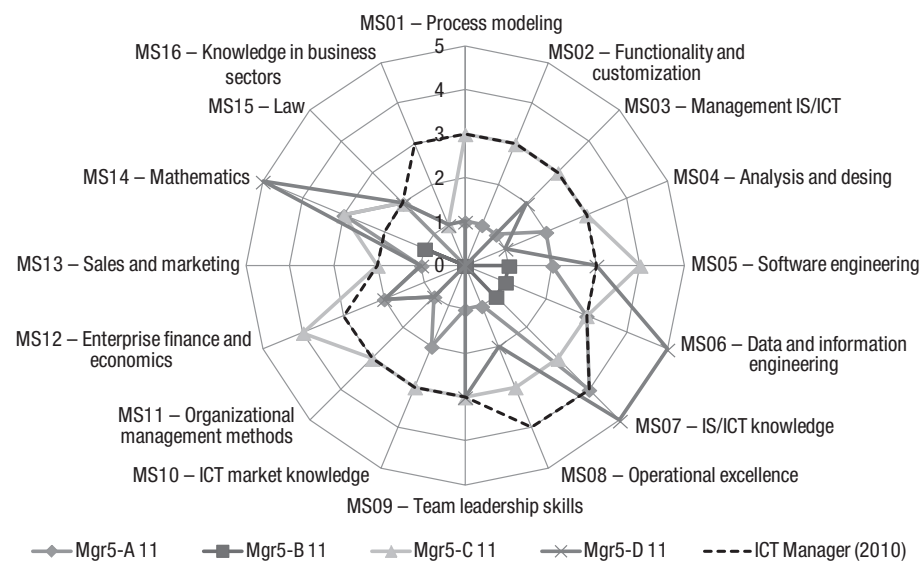

Fig. 6. Knowledge provided by master's fields of study vs demand for knowledge by economic entities for the role of ICT manager in 2010. Source: authors. 
These favourable results are also confirmed by other clusters in master's fields of study where knowledge acquired approaches the requirements of business practice, although the required level of extra training is greater here than for cluster Mgr5-C 11. These fields are Mgr5-D 11 and Mgr5-A 11. The volume of potential knowledge that graduates can acquire during their study is interesting especially for cluster Mgr5-D 11. Respondents stated that their value was at level 5, i.e. maximum knowledge and practical skills. This was recorded for knowledge domains MS06, MS07 and MS14.

\section{Partial conclusions}

The summary graph given in Figure 7, which compares the distance of the cluster of study fields from the requirements of economic entities, is supplementary to the previous analyses of the master's level of education. The left-hand column always gives the data determined in 2006, while the right-hand column gives values determined in the survey in 2011. A quite fundamental difference in the distances in the two surveys can be seen. While, in 2006, the smallest distance between the requirements of practice and the knowledge provided by universities equalled 69 days of extra training (i.e. exceeded the limit of 60 days of extra training), in 2011 the smallest number equalled 23 days, which was well below the limit of 60 days. The requirements are also met in another two clusters where, in the first case, it is necessary to invest in 47 days of extra training and, in the second case, into 56 days of extra training.

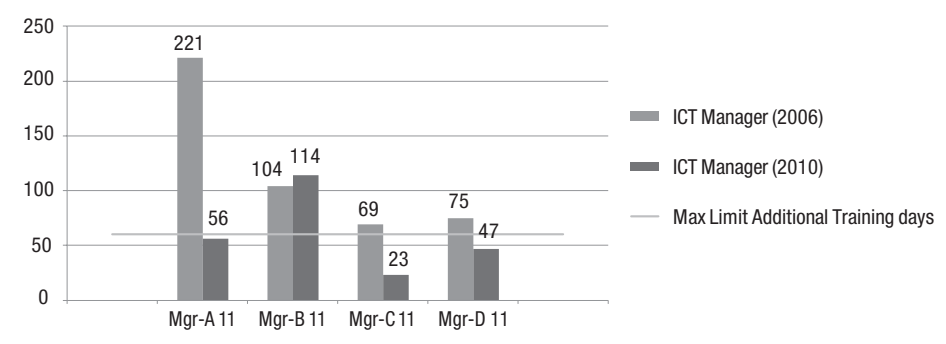

Fig. 7. Gap between the requirements of economic entities on knowledge and the knowledge offered by university graduates

Source: authors.

\section{Conclusions}

Analysis of the results of the two surveys revealed that dynamic developments are occurring in the expectations in the indicators of knowledge, both on the part of demand by economic entities for knowledge of ICT managers and also on the part of knowledge offered by university graduates aspiring to the role of ICT managers.

The results lead to a number of interesting questions and conclusions at which we arrived on the basis of the reactions of respondents to the results of the surveys.

There was a significant change on the part of demand between 2006 and 2010, with a reduction in anticipated knowledge. On the basis of the history of our project, we conclude that an important factor affecting the level demanded consisted in our first 
survey in 2006, whose results were extensively published. On this basis, the economic entities found that their requirements are quite unrealistic under the current conditions of formal education.

A similar conclusion was also valid for university fields of study, which were also extensively published in 2006 and sent to every participating school in the form of a detailed report for the specific field of study. On this basis and in the context of new certification and re-certification of fields of study, the universities worked on their emphasis and contents so that they corresponded better to the requirements of business practice. For the survey in 2011, detailed reports containing analyses of their fields of study are being sent to all participating universities and we anticipate that further development of the fields of study will take place on this basis so as ensure increasing similarity of knowledge offered and required.

The methodology developed for this study and used in it is advantageous for comparing the attained level of knowledge without regard to the area of education and the country in which it is used. The Czech Republic and the example given in this article constitute only one of the potential applications of the developed method.

\section{Acknowledgement}

Paper was processed with contribution of GAČR by handling task GAČR 402/09/0385 "Human Capital in IS/ICT Operations and Development: Competitiveness of Czech Tertiary Education Graduates”.

\section{References}

Agayev, F.; Mamedova, G. 2012. Development of an educational standard of higher education for ICT sphere, in 2012 IV International Conference Problems of Cybernetics and Informatics (PCI). ISBN 978-1-4673-4502-6.

Al-Jabri, I.; Fraihat, M. H. 2005. Professionals in Saudi [online], [cited 12 September 2011]. Available from Internet: http://faculty.kfupm.edu.sa/ MISAC/ imjabri/pub/IIMA1.pdf

Amold, D. J.; Quelch, J. A. 1998. New strategies in emerging markets, Sloan Management Review 40(1): 7-20.

Bilmes, J. A. 1998. A gentle tutorial of the EM algorithm and its application to parameter estimation for Gaussian Mixture and Hidden Markov Models [online], [cited 20 September 2010]. Available from Internet: http://crow.ee.washington.edu/people/bulyko/papers/em.pdf

Brooks, F. P. 1975. The mythical man month. New York: Addison-Wesley.

Crespo, L. V.; Cota, M. P. 2012. Curricular integration of ICT in non-university education levels: model of adjustment and roadmap, in Information Systems and Technologies Book Series: Iberian Conference on Information Systems and Technologies. ISBN 978-1-4673-2843-2

Doucek, P.; Novotny, O.; Pecakova, I.; Vorisek, J. 2007. Human resources in ICT-analysis of supply and demand for ICT professionals in the Czech Republic. Prague: Professional Publishing. ISBN 978-80-86946-51-1 (in Czech).

Doucek, P.; Kunstova, R.; Maryska, M. 2011. Do we have enough ICT specialists in the period of eDependency?, in Creating Solutions for the Individual, Organisations and Society [CD-ROM], 12-15 June 2011, Bled. Maribor: University of Maribor, 1-17. ISBN 978-961-232-247-2. 
EC. 2010. Europe's digital competitiveness report. European Union. ISBN 978-92-79-15829-2. Fernandez, J. 2006. Evaluating, computing, education programs against real world needs, JCSC 21(4): 259-265.

Frinking, E.; Ligtvoet, A.; Lundin, P.; Oortwijn, W. 2005. The supply and demand of e-skills in Europe, prepared for the European Commission and the European e-Skills Forum [online], [cited 20 August 2011]. Available from Internet: http://www.eskills.cedefop.europa.eu.

Gala, L.; Jandos, J. 2010. Enterprise architecture based innovations: competencies perspective, in IDIMT-2010 Information Technology - Human Values, Innovation and Economy, 08-10 September 2010, Jindřichův Hradec. Linz: Trauner, 33-40. ISBN 978-3-85499-760-3.

Hinton, M. 2006. Introducing information management, the business approach. Amsterdam: The Open University/Elsevier. 205 p. ISBN 0-7506-6668-4.

Ihned. 2011. Kariera na trhu práce [online], [cited 1 August 2011]. Available from Internet: http://kariera.ihned.cz/c1-51747890-na-trhu-prace-je-nejzadanejsi-profesi-obsluha-stroju

Johnson, M. 2011. Release management tools: what you need to know for IT operations management. Amazon Media. ISBN 1743041969.

Kotter, J. P. (Ed.). 2009. Vědomí naléhavosti: prvni a nejdůležitějši krok realizace změny. Praha: Management Press. ISBN 978-80-7261-193-5.

Kunstova, R. 2010. Enterprise content management and innovation. Jindřichův Hradec 08.09.2010 - 10.09.2010, in IDIMT-2010 Information Technology - Human Values, Innovation and Economy. Linz: Trauner, 49-56. ISBN 978-3-85499-760-3.

MacLennan, J.; Tang, Z.; Crivat, B. 2009. Data mining with SQL Server ${ }^{\circledR} 2008$. Indianapolis: Wiley Publishing, Inc. ISBN 978-0-470-27774-4.

Manwani, S. 2010. IT-enabled business change: successful management. BCS: The Chartered Institute for IT. 178 p. ISBN 1902505913.

Maryska, M.; Novotny, O.; Doucek, P. 2010. ICT knowledge analysis of university graduates, in IDIMT-2010. Linz: Trauner. ISBN 978-3-85499-760-3.

OECD. 2010. Information technology outlook 2010. Paris: OECD Publishing. 299 p. ISBN 97892-64-08873-3.

OECD. 2011. ICT Skills and Employment [online], [cited 12 september 2011]. Available from Internet: http://www.oecd.org/sti/ICT-employment

Pecakova, I. 2010. Statistika v terénních pri̊zkumech. 2. dopl. vyd. Praha: Professional Publishing. 236 p. ISBN 978-80-7431-039-3.

Porter, M. E. 2008. The five competitive forces that shape strategy, Harvard Business Review 79-93.

Potuzakova, Z.; Mildeova, S. 2011. Systémový přistup ke konceptu flexicurity, Politická ekonomie 59(2): 224-241. ISSN 0032-3233.

Prahalad, C. K.; Hamel, G. 1996. Competing for the future. Boston: Harvard Business School Press. ISBN 0-87584-716-1.

Sołoducho-Pelc, L.; Radomska, J. 2012. The role of human capital in creating competitive advantage based on technology, in IT Research Trends in Transition Economies Proceedings of the International Conference on ICT Management (ICTM 2012), 17-18 September 2012, Wroclaw, Poland. ISBN 978-83-87708-93-1.

Strawman, J. 2004. Computing curricula 2004 overview report including a guide to undergraduate degree programmes, in Computing, Strawman Draft, ACM/AIS/IEEE, 1 [online], [cited 20 August 2011]. Available from Internet: http://www.acm.org/education/curricula.html

Svata, V. 2011. Audit informačního systému. 1. vyd. Praha: Professional Publishing. 220 p. ISBN 978-80-7431-034-8. 
Vojacek, O.; Pecakova, I. 2010. Comparison of discrete choice models for economic environmental research, Prague Economic Papers 19(1): 35-53. ISSN 1210-0455.

Vorisek, J., et al. 2008. Principy a modely ř́zení podnikové informatiky. Praha: Oeconomica. 441 p. ISBN 978-80-245-1440-6.

Zanda, G. 2011. Corporate management in a knowledge-based economy. New York: Palgrave Macmillan. 280 p. ISBN 978-0230294257. http://dx.doi.org/10.1057/9780230355453

Petr DOUCEK (PhD) Prof. heads the Department of System Analysis at University of Economics, Prague. His main topics in research and development work focus on information management, IS/ICT security management, project management and impacts of information society on human.

Milos MARYSKA (PhD) works as a Senior Lecturer at the Department of Information Technologies at the University of Economics, Prague. He focuses on management of economics of business informatics, business Intelligence and ERP systems. In the company ATOS works as a consultant and a head of technical team.

Ota NOVOTNY (PhD) works as an Associate Professor at the Department of Information Technologies, University of Economics, Prague. His main research field concentrates on human resources in IS/ ICT, performance of IS/ICT sector and IS/ICT services measurement. He has been representing Czech Republic in ISO/IEC JTC1 SC7 - Subcommittee for Software and System Engineering. 